\title{
Vienne - Place du Pilori et 2 rue Allmer
}

Opération préventive de diagnostic (2013)

Daniel Frascone

\section{(2) OpenEdition \\ 12 Journals}

Édition électronique

URL : https://journals.openedition.org/adlfi/15142

ISSN : 2114-0502

Éditeur

Ministère de la Culture

Référence électronique

Daniel Frascone, «Vienne - Place du Pilori et 2 rue Allmer » [notice archéologique], ADLFI. Archéologie de la France - Informations [En ligne], Auvergne-Rhône-Alpes, mis en ligne le 30 juillet 2015, consulté le 29 juillet 2021. URL : http://journals.openedition.org/adlfi/15142

Ce document a été généré automatiquement le 29 juillet 2021.

(c) ministère de la Culture et de la Communication, CNRS 


\section{Vienne - Place du Pilori et 2 rue Allmer}

Opération préventive de diagnostic (2013)

Daniel Frascone

\section{NOTE DE L'ÉDITEUR}

Organisme porteur de l'opération : Inrap

1 Cette intervention fait l'objet d'un rapport intermédiaire. Elle représente les deux premières phases réalisées sur les six prévues.

2 Le sondage de la rue Allmer a permis la mise au jour d'une partie de dallage de voie contre laquelle semble s'aligner, dans un axe est-ouest, une maçonnerie de 2,75 m de large pouvant s'apparenter à un rempart.

3 Le second sondage, place du Pilori, a mis en évidence, sur plus de $3 \mathrm{~m}$ d'épaisseur, des remblais variés probablement destinés à rehausser le niveau d'une terrasse antérieure. 


\section{INDEX}

\section{Année de l'opération : 2013}

chronologie https://ark.frantiq.fr/ark:/26678/pcrtxT02uJOogm, https://ark.frantiq.fr/ark:/ 26678/pcrtof7EHNsS2e, https://ark.frantiq.fr/ark:/26678/pcrtZTmusVUU24

lieux https://ark.frantiq.fr/ark:/26678/pcrtSEeAipsBlD, https://ark.frantiq.fr/ark:/26678/ crtB8WDyqd6u9, https://ark.frantiq.fr/ark:/26678/pcrtjNthkbl8NF, https://ark.frantiq.fr/ark:/ 26678/pcrtjdZuW4vx8d

nature https://ark.frantiq.fr/ark:/26678/pcrtWWQS75V5Bc

sujets https://ark.frantiq.fr/ark:/26678/pcrtjclbYvph1S, https://ark.frantiq.fr/ark:/26678/ pcrt1eKrSANesO, https://ark.frantiq.fr/ark:/26678/pcrtKJVpuP3AET, https://ark.frantiq.fr/ark:/ 26678/pcrtDlzbGxWvTo, https://ark.frantiq.fr/ark:/26678/pcrtkP8rR1YLpG, https://

ark.frantiq.fr/ark:/26678/pcrtaGFcSzXQ5x, https://ark.frantiq.fr/ark:/26678/pcrtMmh3cNfKb3

\section{AUTEURS}

DANIEL FRASCONE

Inrap 